\title{
Stability of Spodoptera litura nucleopolyhedrovirus in sodium dodecyl sulphate
}

\author{
Nazli-Huda, I. ${ }^{1}$, Sajap, A. S. ${ }^{2 \star}$ and Lau, W. H. ${ }^{1}$ \\ ${ }^{1}$ Department of Plant Protection, Universiti Putra Malaysia, 43400 UPM Serdang, Selangor D.E., Malaysia. \\ ${ }^{2}$ Department of Forest Management, Universiti Putra Malaysia, 43400 UPM Serdang, Selangor D.E., Malaysia.
}

Accepted 1 February, 2012

\begin{abstract}
Sodium dodecyl sulfate (SDS) is a foaming agent used to extract occlusion bodies (OBs) of baculoviruses from infected cells or tissues of an insect. However, these OBs may be damaged by SDS at certain concentrations. In this study, the impact of different concentrations of SDS on OBs of Spodoptera litura nucleopolyhedrovirus (SpltNPV) was determined. Even though the number of OBs harvested increased with the increase in the concentration of SDS used in the extraction, the percentage of damaged OBs also increased correspondingly as detected through scanning electron microscope (SEM) photomicrographs. The result also indicates that infectivity of SpltNPV on second instars of S. litura larvae reduced significantly with an increase of SDS concentration used in the treatment. Among the four concentrations of SDS tested, SDS at $0.1 \%$ was able to release more quality virus. Thus, SDS of less than $0.1 \%$ is recommended for obtaining optimum number of quality OBs.
\end{abstract}

Key words: Sodium dodecyl sulfate, Spodoptera litura nucleopolyhedrovirus, occlusion body, polyhedron envelope.

\section{INTRODUCTION}

Sodium dodecyl sulphate (SDS) is an anionic surfactant capable of disrupting non-covalent bonding in proteins and denaturing them with most proteins that lose their functions completely or partially in its presence (Yamada et al., 1998). In insect pathological works, SDS has been used routinely for extracting and purifying baculovirus polyhedra from infected cells of diseased insects for bioassays (Thorne et al., 2007). The compound lyses cells and expose the DNA. Currently, sodium dodecyl sulfate is being incorporated in polyacrylamide gel electrophoresis (SDS-PAGE) for analyzing baculovirus structural proteins (Scharnhorst and Weaver, 1980; Zuidema et al., 1989). However, exposing baculoviruses, particularly nucleo-polyhedroviruses, to SDS has been shown to be damaging to the polyhedra (Linda et al., 2003). Lee-ju and Hou (2009) also reported that SDS

*Corresponding author. E-mail: ahsaid@putra.upm.edu.my.

Abbreviations: SDS, Sodium dodecyl sulfate; OBs, occlusion bodies. was suppressive to Bombyx mori nucleopolyhedrovirus (BmNPV) infecting silkworm cell lines, Bm-N. The damaged polyhedra lost their polyhedron envelopes (PEs) and the virions dislodged from the polyhedron matrix, leaving empty spaces that were previously occupied by the occluded virions (Linda et al., 2003). The PE is vital to the biological activity of a polyhedron, as it ensures the retention of virions within the polyhedron complex (Gross et al., 1994). A Malaysian isolate of Spodoptera litura nucleopolyhedrovirus (SpltNPV), pathogenic to its host $S$. litura (Sajap et al. 2000), has also been subjected to SDS in lysing cells of the host insect for harvesting the occlusion bodies (OBs). However, no attempt to determine the quality of the OBs produced through the process had been made. Thus, this study was carried out to determine the impact of SDS on the quality of OBs of SpltNPV.

\section{MATERIALS AND METHODS}

Propagation of SpltNPV

Larvae for virus propagation were reared on leaves of Hydrocotyles 
sibthorpioides, locally known as pegaga. The leaves were surfacesterilized by soaking them in $0.5 \%$ sodium hypochlorite for three minutes and rinsed twice in distilled water. The leaves were then cut using a cork borer into $1 \mathrm{~cm}$ discs. Ten micro-liter of virus suspension was pipetted onto each leaf disc and air dried on an aluminum foil in a lamina air flow. Third instars $S$. litura that have been starved for $24 \mathrm{~h}$ prior to the experiment were individually fed with a piece of contaminated leaf disc in a Petri dish. After consuming the entire leaf disc, the larvae were supplied daily with uncontaminated leaves. Larvae with polyhedrosis symptom, five to seven days after treatment, were collected and used for the following experiments.

\section{Preparation of SDS}

SDS Sigma ${ }^{\circledR}$ of electrophoresis grade, $\geq 98.5 \%$ (GC), was used in the experiment. One hundred grams of SDS was dissolved in 900 $\mathrm{ml}$ of distilled water warmed to $60^{\circ} \mathrm{C}$ to assist dissolution. The $\mathrm{pH}$ was adjusted to 7.2 by adding a few drops of concentrated hydrochloric acid and the volume was adjusted to $1 \mathrm{~L}$ in distilled water. The solution was then dispensed into aliquots and kept at room temperature of $27^{\circ} \mathrm{C}$. The SDS was diluted to $0.2,0.1,0.005$ and $0.0025 \%$. The effects of the SDS on the OBs were observed under light and electron microscopes. Each concentration was bioassayed against third instars of $S$. litura

\section{SDS treatment}

S. litura nucleopolyhedrovirus were isolated from diseased larvae by homogenizing $1 \mathrm{ml}$ of distilled water. This homogenate was treated with SDS following a procedure that was modified from a standard technique used for routine purification and dissolution of NPV polyhedra (Jones, 2000). Two volumes of SDS at different concentrations were added and incubated for a period of $30 \mathrm{~min}$. The homogenate was centrifuged at $1,000 \mathrm{xg}$ for $15 \mathrm{~min}$. The pellet was discarded and the supernatant was collected and centrifuged at $10,000 \mathrm{xg}$ for $15 \mathrm{~min}$. The pellet containing virus was collected by washing twice with distilled water and spinning at $10000 \mathrm{xg}$ for 15 min. The OBs was observed under a light microscope and the number was calculated by using a counting chamber following Wigley (1980) equation.

\section{Scanning electron microscope (SEM)}

The virus was treated with four concentrations of SDS $(0.0025$, $0.005,0.1$ and $0.2 \%$ ). The viral suspension was maintained in the SDS for $30 \mathrm{~min}$. Samples of pellet (debris) and supernatant (homogenate of virus) from each SDS treatment and untreated virus were processed for SEM examination. Samples were cut into $1 \mathrm{~cm}^{3}$ before fixing with $4 \%$ glutaraldehyde for 12 to $24 \mathrm{~h}$ at $4{ }^{\circ} \mathrm{C}$. After washing for three times with $0.1 \mathrm{M}$ cacodylate buffer at $4^{\circ} \mathrm{C}$ for $10 \mathrm{~min}$ each, the samples were fixed with $1 \%$ osmium tetroxide at $4^{\circ} \mathrm{C}$ for $2 \mathrm{~h}$. Washing process was repeated twice by using $0.1 \mathrm{M}$ cacodylate buffer for $10 \mathrm{~min}$ each. The samples were dehydrated through a series of acetone, rinsed once in 35, 50, 75 and $95 \%$ for $10 \mathrm{~min}$ each and three times in $100 \%$, for 15 min each. Samples were then transferred into specimen baskets before being placed into the critical point dryer for $30 \mathrm{~min}$. The specimens were stuck onto the stub using double side tape or colloidal silver, and gold coated in a sputter before being examined under SEM. 10 photomicrographs were taken randomly from each treatment and the number of damaged and undamaged OBs were assessed and expressed as percentages. All photomicrographs were taken at $5000 \times$ magnification for standardization.

\section{Bioassay}

Virus suspension that had been maintained for $30 \mathrm{~min}$ in four SDS concentrations $(0.005,0.01,0.1$ and $0.2 \%)$ was bioassayed on third instars of $S$. litura following the method described by Jones (2000). The $H$. sibthorpioides leaf discs were treated with $2.4 \times 10^{7}$ OBs of SpltNPV (SDS-treated or untreated). They were then allowed to dry for 5 min. One larva was put in a Petri dish containing either treated or untreated leaf disc. After the larvae had consumed the entire leaf disc, they were given fresh leaves. Larval mortality was recorded daily. 10 larvae were used for each treatment and each treatment was replicated 10 times on separate occasions. Thus, a total of 100 larvae were used for each treatment.

\section{Data analysis}

The number of damaged OBs after treatment was determined and percentage of damaged OBs was calculated as (number of damaged OBs/total OBs scored) $\times 100$. The mortality rate of infected larvae was subjected to arcsine transformation before the impact of the treatments was evaluated using a two-way analysis of variance (SAS, 2004) and the means were compared using Tukey's Studentized range test $(\alpha=0.05)$.

\section{RESULTS}

\section{Symptoms of infection}

The infected larvae showed typical polyhedrosis symptoms. The integument became flaccid and turned pinkish. The infected larvae ceased feeding after three days post inoculation. The dorsal, lateral and ventral side of the larvae turned to pink colour as compared to the green colour of the healthy larvae after five days of infection. The larvae regurgitated and ruptured after seven days post inoculation, releasing white body fluid that was filled with occlusion bodies (OBs). The texture of the fluid became smoother when higher concentrations of SDS were added. The homogenate became less clumpy which eased the counting of OBs.

\section{Counts of normal and damaged OBs}

The SDS treatments evidently increased the amount of OBs harvested (Table 1). Average number of OBs harvested increased by one-fold when treated with $0.1 \%$ SDS and four folds, from $1.2 \times 10^{7}$ per $\mathrm{ml}$ in untreated virus to more than $4.5 \times 10^{7}$ per $\mathrm{ml}$, when the virus was treated with more than $0.20 \%$ SDS. Counts of damaged OBs under SEM showed that the percentage damaged OBs in treatments with 0.0025 and $0.005 \%$ SDS were not significantly different from those in untreated virus. A significant difference was observed for treatments with more than $0.10 \%$ SDS. OBs treated with $0.0025 \%$ SDS resulted in $1.55 \%$ of damaged OBs and the damage increased by $33.01 \%$, with a total of $53.81 \%$ damaged OBs, when the concentration of SDS was increased to $0.20 \%$. The untreated OBs also contained $20.8 \%$ of damaged OBs. The percentage of damaged OBs in the 
Table 1. Estimated number of occlusion bodies (OBs) harvested after treatment as seen under a light microscope and percentage of damaged OBs in $10 \mathrm{ul}$ of homogenate and debris as seen under a scanning electron microscope

\begin{tabular}{lccc}
\hline Treatment & $\begin{array}{c}\text { Number of OBs under light } \\
\text { microscope in } \times \mathbf{1 0}^{\mathbf{7}} \text { per } \mathbf{~ m l} \\
(\text { Mean } \pm \text { SE) }\end{array}$ & $\begin{array}{c}\text { Percentage of damaged } \\
\text { OBs in homogenate (SEM) } \\
\text { (Mean } \pm \text { SE) }\end{array}$ & $\begin{array}{c}\text { Percentage of damaged } \\
\text { OBs in debris (SEM) } \\
\text { (Mean } \pm \text { SE) }\end{array}$ \\
\hline Untreated & $1.20 \pm 0.02^{\mathrm{a}}$ & $20.80 \pm 2.92^{\mathrm{a}}$ & $12.97 \pm 1.51^{\mathrm{a}}$ \\
$0.0025 \%$ SDS & $1.10 \pm 0.03^{\mathrm{a}}$ & $22.37 \pm 0.78^{\mathrm{a}}$ & $15.18 \pm 2.13^{\mathrm{a}}$ \\
$0.005 \%$ SDS & $1.20 \pm 0.02^{\mathrm{a}}$ & $23.05 \pm 1.02^{\mathrm{a}}$ & $15.70 \pm 1.83^{\mathrm{a}}$ \\
$0.10 \%$ SDS & $4.20 \pm 0.01^{\mathrm{b}}$ & $41.87 \pm 2.73^{\mathrm{b}}$ & $38.79 \pm 4.77^{\mathrm{b}}$ \\
$0.20 \%$ SDS & $4.50 \pm 0.02^{\mathrm{b}}$ & $53.81 \pm 3.80^{\mathrm{c}}$ & $38.99 \pm 3.64^{\mathrm{b}}$ \\
\hline
\end{tabular}

*Means with the same letters in the same column indicate no significant difference at $\mathrm{P}<0.05$ (Tukey's test). SDS, Sodium dodecyl sulfate.
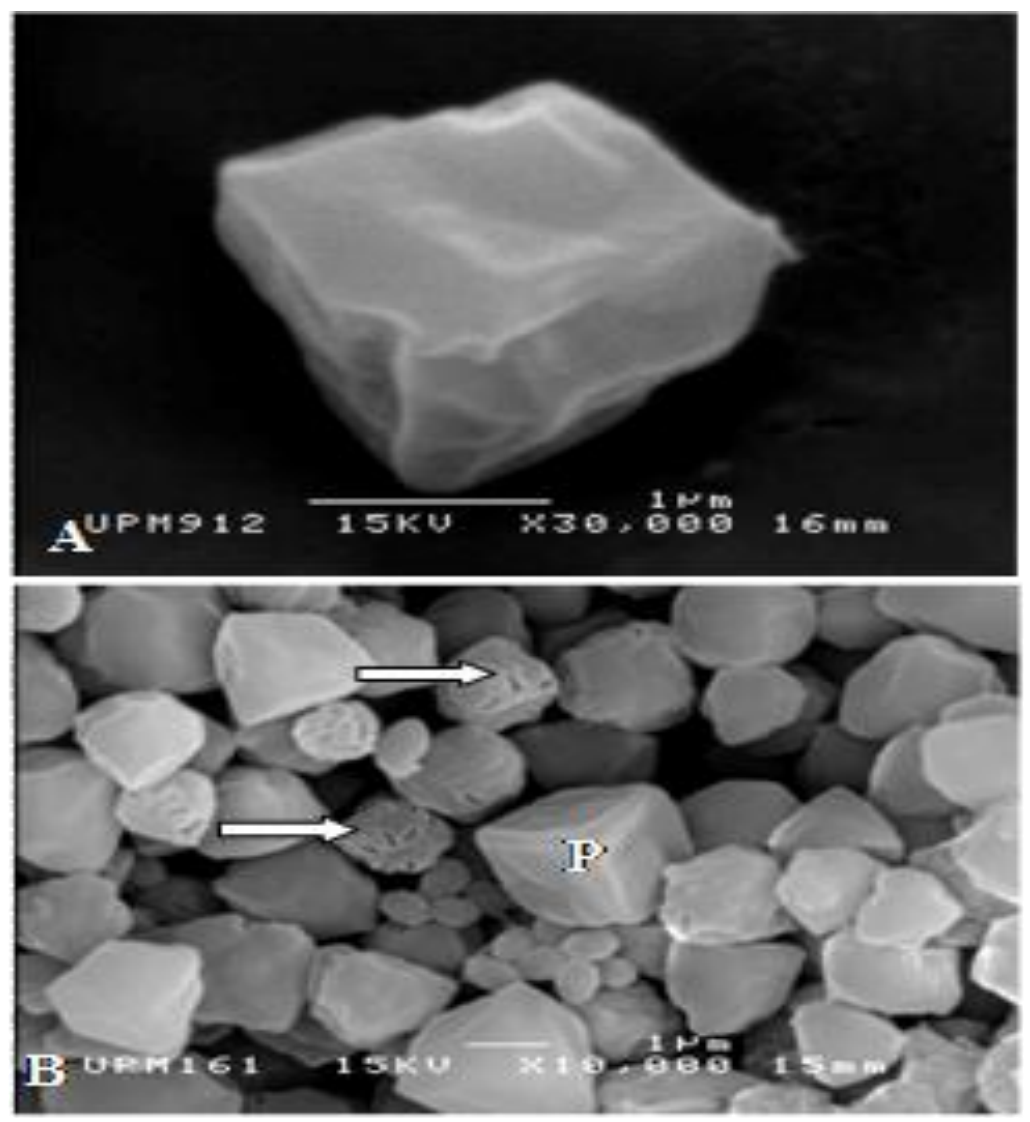

Figure 1. (A) Undamaged $O B$ with smooth surfaces; $(B)$ the damaged OBs with pitted surfaces. $\mathrm{P}$, Polyhedra; bar $=1 \mu \mathrm{m}$. OBs, Occlusion bodies.

debris also increased with increasing concentration of SDS used in the treatment. The damaged OBs increased by $26 \%$, from $12.97 \%$ in untreated to $38.99 \%$ in $0.20 \%$ SDS-treated virus.

\section{Scanning electron microscope (SEM)}

We examined the treated and untreated OBs harvested from the homogenate and debris of larval tissues. Some of the OBs in the SDS treated-homogenate had their virions dislodged from the protein matrices leaving empty spaces in the OBs (Figure 1). These virions dislodged and damaged $\mathrm{OBs}$ were evidently smaller than the normal OBs. Some of the OBs were not able to complete the formation process before the cell rupture. Figure 2 shows normal and damaged OBs after treatment with different concentrations of SDS. The normal OBs appea- 

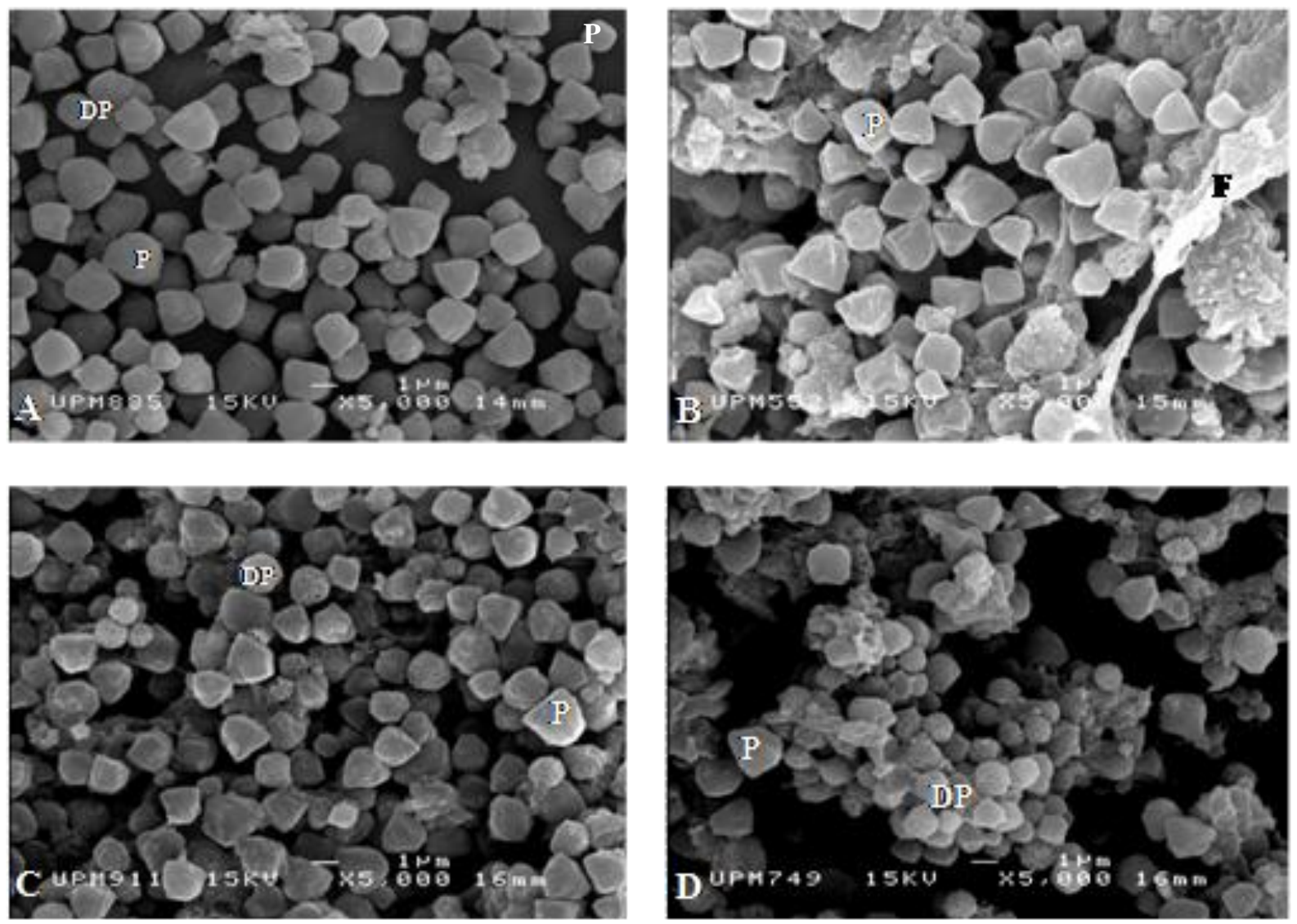

Figure 2. (A) Polyhedra in homogenate of $0.0025 \%$ SDS treated virus; (B) polyhedra in debris of $0.0025 \%$ SDS treated virus; (C) polyhedra in homogenate of $0.2 \%$ SDS treated virus; (D) polyhedra in debris of $0.2 \%$ SDS treated virus. DP, Damaged polyhedra; F, fat tissue; P, polyhedral; SDS, sodium dodecyl sulfate OBs, occlusion bodies. Bar $=1 \mu \mathrm{m}$.

red smooth, while the damaged OBs had pitted surfaces. The proportion of damaged OBs was evidently higher in homogenate that was treated with higher concentration of SDS (Figure 2D) than those that had been treated with lower concentration of SDS (Figure 2A).

\section{Bioassay}

The result of the bioassay shows that SDS significantly reduced infectivity of the SpltNPV when it was used in a concentration higher than $0.10 \%$. The mortality of the larvae dropped by $24 \%$, from $96 \%$ in the untreated to $72 \%$ in the $0.10 \%$ SDS-treated virus. $\mathrm{LT}_{50}$ values increased significantly from 3.51 to 4.34 days when the concentration of SDS was raised higher than $0.10 \%$ (Table 2). At concentration of $0.20 \%$ SDS, $68 \%$ mortality was recorded.

\section{DISCUSSION}

Polyhedron envelope (PE), a membrane-like structure that surrounds occlusion body $(\mathrm{OB})$, stabilizes the virions in the environment (Blissard and Rohrmann, 1990). In highly alkaline conditions, the PE may be degraded and consequently reduce the infectivity of the virus. The $\mathrm{LT}_{50}$ values of $S$. litura larvae treated with SpltNPV increased to about four folds when $\mathrm{pH}$ of the viral suspension was raised from seven to eleven days (Sajap et al., 2007). In a natural condition, the $\mathrm{pH}$ in the larval gut system, varying between 10 and 11 , catalyses the rupturing of the $\mathrm{PE}$, thereby releasing the virions (Harrap, 1972) and subsequently initiating infections in the host cells. In this study, dissolution of OBs was observed when SpltNPV was treated with SDS. Even though the yield of OBs harvested increased with the increase in the concentration of SDS used, percentage of damaged OBs also increased. Result from this study shows that SDS of more than $0.1 \%$ is not suitable for extracting OBs from larval cadavers as it increases the number of damaged OBs. Severity of damages caused by SDS treatment on OBs, however, varied with the types of nucleopolyhedroviruses and to certain extent, the protocols used in the experiment. A less severe damage was observed on Helicoverpa armigera nucleopolyhedrovirus (HaSNPV) treated with $0.5 \%$ SDS for 30 min as it only caused 20\% damaged virus (Linda et al., 2003). This 
Table 2. Percentage mortality and $\mathrm{LT}_{50}$ values of SpltNPV-infected Spodoptera litura larvae after treatment with different SDS concentrations.

\begin{tabular}{lcc}
\hline Treatment & $\begin{array}{c}\text { Mortality (\%) } \\
\text { (Mean } \pm \text { SE) }^{\star}\end{array}$ & $\begin{array}{c}\mathbf{L T}_{50} \text { (days) } \\
(\mathbf{9 5 \%} \text { C.I) }\end{array}$ \\
\hline Water & $0^{\mathrm{a}}$ & 0 \\
Untreated NPV & $96.00 \pm 1.63^{\mathrm{b}}$ & $3.51(3.29-3.72)$ \\
$0.005 \%$ SDS & $95.00 \pm 1.66^{\mathrm{b}}$ & $3.45(3.24-3.66)$ \\
$0.01 \%$ SDS & $92.00 \pm 2.91^{\mathrm{b}}$ & $3.71(3.50-3.92)$ \\
$0.10 \%$ SDS & $72.00 \pm 4.67^{\mathrm{c}}$ & $4.14(3.93-4.35)$ \\
$0.20 \%$ SDS & $68.00 \pm 5.33^{\mathrm{c}}$ & $4.34(4.13-4.54)$ \\
\hline
\end{tabular}

*Means with the same letters indicate no significant difference at $P<0.05$ (Tukey's test). ${ }^{* *}$ Estimates of $\mathrm{LT}_{50}$ (days) calculated from means of 10 replicates with 10 larvae per treatment. No mortality was recorded from negative control (water).

shows that different types of the NPV could possibly posses a different degree of tolerance to SDS. Severity of damages on the OBs was also reflected on the infectivity of the resultant OBs. Third instars $S$. litura bioassayed against OBs that had been treated with more than $0.1 \%$ SDS had significantly lower mortality than those that had been treated with untreated virus or virus in less than $0.1 \%$ SDS. This result confirms that SDS, when used at high concentration, deleteriously affects OBs of SpltNPV. It is recommended that SDS of less than $0.1 \%$ should be used to obtain optimum quality of OBs.

\section{ACKNOWLEDGEMENTS}

We thank Malaysian Agricultural Research and Development Institute (MARDI) for supplying the S. litura larvae and the Institute of Biosciences (IBS), Universiti Putra Malaysia for providing technical services in the electron microscopy. We also thank Dr. Roslan Mohamad Kassim for his statistical advice.

\section{REFERENCES}

Blissard GW, Rohrmann GF (1990). Baculovirus diversity and molecular biology. Ann. Rev. Entomol. 35: 127-155.

Gross CH, Russell RLQ, Rohmann GF (1994). Orgyia psedosutgata baculovirus and polyhedron envelope protein genes: analysis of their relative expression levels and role in polyhedron structure. J. Gen. Virol. 10(75): 1115-1123.

Harrap KA (1972). The structure of nuclear polyhedrosis viruses: I. The inclusion body. Virology, 50: 114-123.

Jones KA (2000) Bioassays of Entomopathogenic Viruses. In Navon A, Ascher KRS (eds). In Bioassays of entomopathogenic microbes and nematodes. CABI Publishing, UK. pp. 95-140.

Lee-ju C, Hou RF (2009). Factors enhancing Bombyx mori nuclear polyhedrosis virus infection in vitro. J. Appl. Entomol. 113: 103-106.
Linda HLL, Nielsen K, Steven R (2003). Sensitivity of Helicoverpa armigera nucleopolyhedrovirus polyhedra to sodium dodecyl sulfate. Biol. Control. 26: 57-67.

Sajap AS, Kotulai JR, Hong LW, Bakir MA, Norani AS, Kadir HA (2000). Pathogenicity and characteristics of Spodoptera litura nucleopolyhedrovirus from Peninsular Malaysia. Pertanika J. Trop. Agric. Sci. 23: 23-28.

Sajap AS, Bakir MA, Kadir HA, Samad NA (2007). Effect of pH, rearing temperature and sunlight on infectivity of Malaysian isolate of nucleopolyhedrovirus to larvae of Spodoptera litura (Lepidoptera: Noctuidae). Int. J. Trop. Insect Sci. 27: 108-113.

SAS (2004). SAS System Viewer. SAS Institute, Cary, NC.

Scharnhorst DW, Weaver RF (1980). Structural analysis of the matrix protein from the nuclear polyhedrosis virus of Heliothis zea, Virology, 102: 1468-472.

Thorne CM, Otvos IS. Conder N, Levin, DB (2007). Development and evaluation of methods to detect nucleopolyhedrovirusesin larvae of the douglas-fir tussock moth, Orgyia pseudotsugata (McDunnough) Appl. Environ. Microbiol. 73: 1101-1106.

Wigley PJ (1980). Practical: Counting Microorganism. In Kalmakaff J, Longworth JF (eds.). Microbial Control of Insect Pests. New Zealand Dept. Sci. Ind. Res. Bull. 228: 29-35.

Yamada T, Ohta H, Masuda T, Ikeda M, Tomita N, Ozawa A, Shioi Y, Takamiya K (1998). Purification of a novel type of SDS-dependent protease in maize using monoclonal antibody. Plant Cell Physiol. 39: 106-114.

Zuidema D, Klinge-Roode EC, Van Lent JW, Vlak JM (1989). Construction and analysis of an Autographa californica nuclear polyhedrosis virus mutant lacking the polyhedral envelope. Virology, 173: 98-108. 